\title{
Frontières
}

\section{Les éternels pigistes}

Simples mortels

\section{Jeannette Rioux et Johanne Cadieux}

Volume 15, numéro 1, automne 2002

Délires urbains, dangers de mort

URI : https://id.erudit.org/iderudit/1073911ar

DOI : https://doi.org/10.7202/1073911ar

Aller au sommaire du numéro

Éditeur(s)

Université du Québec à Montréal

ISSN

1180-3479 (imprimé)

1916-0976 (numérique)

Découvrir la revue

Citer ce document

Rioux, J. \& Cadieux, J. (2002). Les éternels pigistes : simples mortels. Frontières, 15(1), 69-70. https://doi.org/10.7202/1073911ar

Ce document est protégé par la loi sur le droit d'auteur. L'utilisation des services d'Érudit (y compris la reproduction) est assujettie à sa politique d'utilisation que vous pouvez consulter en ligne.

https://apropos.erudit.org/fr/usagers/politique-dutilisation/
Cet article est diffusé et préservé par Érudit.

Érudit est un consortium interuniversitaire sans but lucratif composé de l’Université de Montréal, l’Université Laval et l’Université du Québec à Montréal. Il a pour mission la promotion et la valorisation de la recherche. https://www.erudit.org/fr/ 


\section{LES ÉTERNELS PIGISTES SIMPLES MORTELS}

\section{Jeannette Rioux et Johanne Cadieux, Alfred Dallaire.}

Cinq comédiens, un auteur : des pigistes. Une troupe de théâtre, une pièce, une troisième saison qui se présente, les coffres sont vides.

Avril 2002. Une première rencontre avec Isabelle Vincent. Nous avons tout de suite un coup de cœur pour cette jeune femme sensible, enthousiaste, engagée et dont le charisme ne laisse personne indifférent. Au nom de la troupe, elle sollicite notre soutien financier pour la production de la pièce le Rire de la mer, troisième vague, où elle joue le rôle de Pénélope. Alfred Dallaire (oui, les salons funéraires), accepteraientils de soutenir le projet de la troupe Les Éternels Pigistes ${ }^{1}$ ? Le deuil est un sujet important dans cette pièce: Pénélope apprend qu'elle n'en a plus pour longtemps. Une aventure autour du monde, à travers les époques, un humour fin.

Les pigistes avaient eu auparavant l'idée d'organiser deux événements-bénéfice au cours desquels des personnalités de la scène culturelle avaient accepté de lire des lettres sur les thèmes de l'amour et du voyage, deux autres des thèmes principaux du Rire de la mer. Impressionnées par la qualité de leur œuvre, nous avons décidé de les appuyer dans l'organisation d'une troisième série de soirées-bénéfice, les 15 et 16 septembre. L' « autre » thème s'imposait : celui du deuil. L'endroit? Chez nous. Au centre culturel Alfred-Dallaire. Qu'elle serait la réponse? Les gens allaient-ils y venir pour entendre des lettres qui parlent de deuils?

Une salle comble, le dimanche soir. Puis, il fallut ajouter des sièges, le lundi soir. Malgré le nombre considérable de spectateurs, un ambiance des plus intimistes. Les comédiens, courageux, nous ont livré un moment intime, spécial, marquant de leur vie. Les boîtes de mouchoirs de papier ont abondamment circulé. Les émotions prenaient toute sortes de formes. Pas seulement

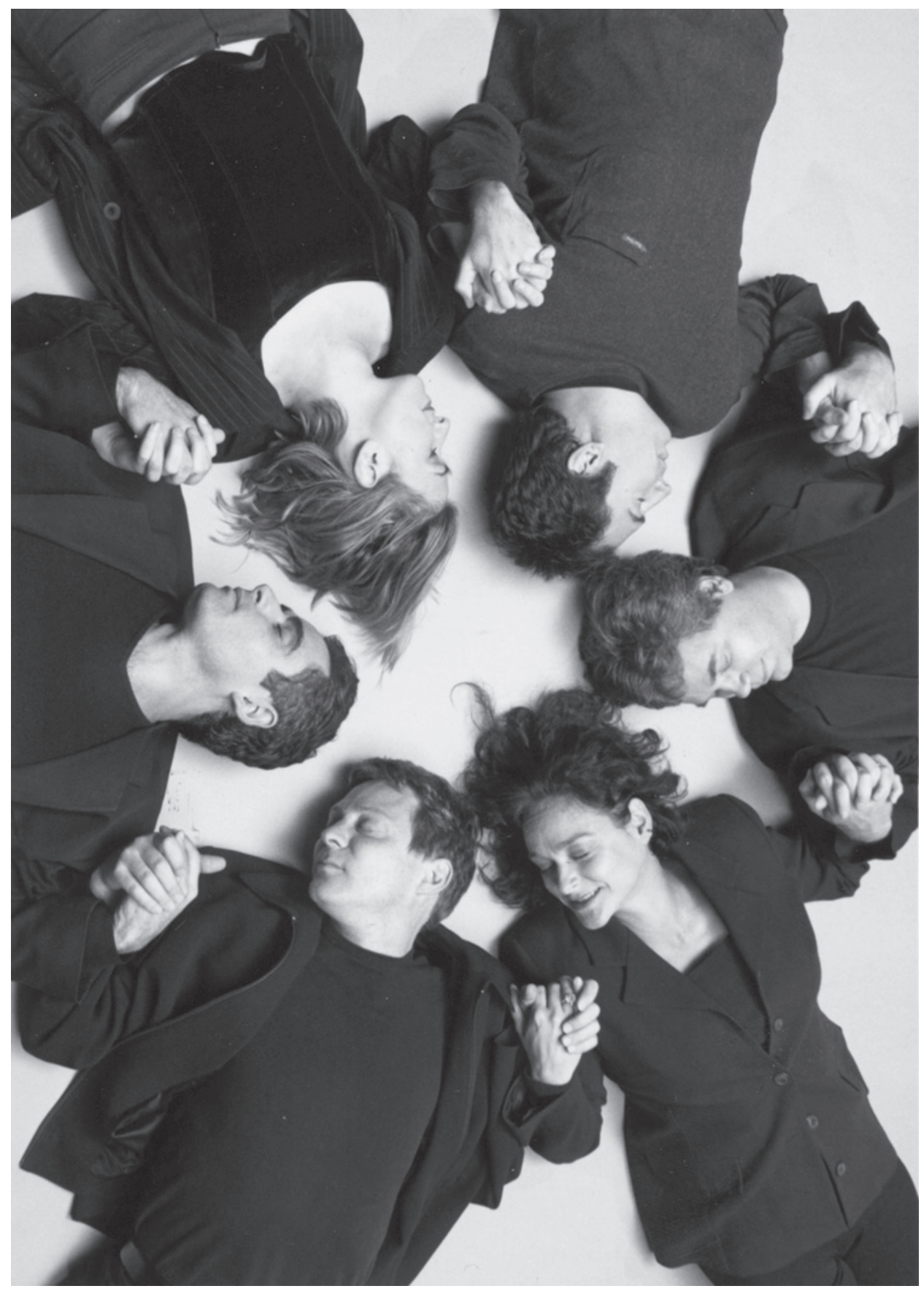


tristes et lourdes, mais aussi tendres et douces, passionnées et révoltées, paisibles et réconciliées.

Et le public, courageux aussi selon Isabelle Vincent qui adressait le mot de bienvenue à l'assistance: "Ça prend quand même une certaine dose de courage pour venir entendre des lettres qui portent sur le deuil. C'est vrai. Mais les occasions de se rassembler simplement, pour partager ensemble un moment d'intimité ne sont pas si fréquentes de nos jours.[...] Je souhaite que tous ces mots vous touchent, vous nourrissent, vous atteignent comme ce fut le cas pour Patrice et moi. »

Patrice Coquereau, organisateur de l'événement avec Isabelle Vincent, a déclaré que cette soirée avait non seulement servi de moyen de financement pour la troupe, mais qu'elle avait été pour lui une expérience enrichissante et libératrice au plan personnel et surtout, un moment privilégié d'échange, dans une société où règne un individualisme généralisé.

Aucune censure. Le sujet du deuil était abordé au sens large. Chacun en présentait une facette qui le concernait, au moment où il en était dans sa vie. Chaque expérience de deuil est unique, mais les manières de l'apprivoiser sont multiples. L'humour, le cynisme, la rage, le stoïcisme et l'abandon sont autant de réponses à la Grande Fau- cheuse, au départ d'un ami, à la fin d'une carrière, à un projet avorté, à une rupture amoureuse et aux nombreux deuils parsemant nos vies. Alors que Louise Latraverse disait adieu à son jardin, Daniel Parent tentait avec sarcasme de goûter au potentiel de sa «nouvelle» liberté. Karen Elkin portait en elle le deuil d'un nourrisson, Suzanne Lemoine rendait hommage à Lucie, Julie Lavergne se souvenait de ses folies de jeunesse. Marcel Pomerlo osait enfin s'adresser à son frère Momo, JeanFrançois Casabonne devenait la mère et le père de sa mère le temps d'une nuit essoufflée $^{2}$, Lynda Roy lisait avec émotions un extrait du texte La mort est un chat $^{3}$, écrit par Serge Bouchard, et Clémence Desrochers faisait visiter sa maison de campagne à sa maman qui aurait cent deux ans. Participaient aussi Sylvie Drapeau, France Arbour, Carole Giradeau, Rita Lafontaine, Lou Arteau, Hélène Bourgeois Leclerc, Brigitte Paquette, Christine Séguin, Guy Vaillancourt, Annie St-Pierre, Carole Huynh Guay, Christian Bégin, Patrice Coquereau, Geneviève Néron, Aubert Pallascio, Isabelle Vincent, Rosine Chouinard-Chauveau, Violette Chauveau et Marie-Andrée Corneille. Pour terminer ces soirées sur une note réconfortante, Robert Paquette, accompagné de sa guitare, nous a offert deux chansons. Il nous a invité à chanter avec lui, nous ramenant à nos souvenirs joyeux et intimes de regroupement amical autour d'un feu de camp.

Ce fut deux soirées inoubliables. Merci, Éternels Pigistes. Votre œuvre suscite paroles, échanges, émotions. Meilleur succès à la troisième saison du Rire de la mer qui a déjà séduit les critiques !

\section{Notes}

1. Motivés par leur sens de la créativité, Christian Bégin, Marie Charlebois, Patrice Coquereau, Pier Paquette, Pierre-Michel Tremblay et Isabelle Vincent se regroupaient en 1996 pour la création du Jeu du pendu, une pièce de Pierre-Michel Tremblay. Peu de temps après, le groupe créait la compagnie des Éternels Pigistes et récidivait avec Quelques Humains en 1998, suivi de Délirium en 2000 et enfin, de la création du Rire de la mer, autre réussite qui, après deux séries de représentations à Montréal et une tournée de 25 villes à travers la province, a été présenté pour une troisième saison à La Licorne du $1^{\text {er }}$ octobre au 9 novembre 2002.

2. Jean-François, Casabonne, Jésus de Chicoutimi: une perséide de Damas, Éditions du Silence.

3. J. Légaré (dir.) (2001). Jamais de la vie, écrits et images sur les pertes et les deuils, Montréal, Les éditions du Passage.

\section{L'AUTRE VILLE}

Il y a plusieurs solitudes et elles s'entrecroisent - dit-il - en haut et en bas

et d'autres au milieu; différentes ou pareilles, inéluctables, obligées, ou bien plutôt choisies, ou bien plutôt libres - entrecroisées toujours.

Mais, profondément au centre, il y a l'unique solitude - dit-il; une ville creuse, à peu près sphérique, sans aucune de ces réclames électriques multicolores, magasins, motocyclettes, avec une lumière blanche, vide, brumeuse, interrompue par le scintillement de signaux inconnus. Dans cette ville habitent depuis des années les poètes. Ils marchent sans bruit, les bras croisés,

ils se rappellent les choses qui se sont passées, indéterminées, oubliées, des mots, des paysages,

eux consolateurs de monde, toujours inconsolés, chassés par les chiens, les hommes, les mites, les souris, les étoiles, chassés aussi par leurs propres paroles dites et non dites. 